\title{
Economic Effects of Exposure to Bovine Viral Diarrhea Virus on Dairy Herds in New Zealand
}

\author{
C. Heuer, ${ }^{* 1}$ A. Healy, $\dagger$ and C. Zerbini* \\ *EpiCentre, Institute of Veterinary, Animal and Biomedical Sciences, Massey University, New Zealand \\ †Faculty of Veterinary Sciences, University of Dublin, Ireland
}

\begin{abstract}
The economic loss to dairy farmers associated with bovine viral diarrhea virus (BVDV) is believed to be high in New Zealand, but no estimates are yet available. The aim was therefore to estimate the economic loss associated with BVDV in dairy herds in New Zealand. Bulk tank milk (BTM) from a random sample of 590 herds from the Northland, Bay of Plenty, and Waikato regions was tested for antibody against BVDV. The inhibition percentage (sample to positive ratio), based on a threshold validated in an earlier study, was used to indicate herd-level infection. Herd reproductive indices, herd lactation-average somatic cell counts, and herd average production of milk solids were regressed on BTM inhibition percentage. Herd averages of the overall annual culling rate, the rate of culling because of failure to conceive, the proportion of physiological interservice intervals, the first-service conception rate, the pregnancy rate at the end of mating, and somatic cell counts were not associated with BVDV antibody in BTM. Abortion rates, rates of calving induction, the time from calving to conception, and the number of services per conception increased, however, whereas milk production decreased with increasing BVDV antibody in BTM. The results indicated significant reproductive and production loss associated with the amount of BVDV antibody in BTM. Total loss attributable to infection with BVDV was similar to reports from other countries and estimated as NZ\$87 per cow and year in affected herds, and NZ $\$ 44.5$ million per year for the New Zealand dairy industry based on an estimated $14.6 \%$ affected herds. The loss estimate excludes added cost and negative consequences with respect to animal welfare attributable to increased induction rates, and a greater incidence of production disease because of BVD-induced immune suppression.
\end{abstract}

Received April 4, 2007.

Accepted August 19, 2007.

${ }^{1}$ Corresponding author: c.heuer@massey.ac.nz
Key words: bulk tank antibodies against bovine viral diarrhea virus, economic effects, herd-level analysis, partial budget

\section{INTRODUCTION}

Bovine viral diarrhea virus (BVDV) is considered a worldwide pathogen with moderate to high prevalence of both exposed herds and seropositive animals within herds (Reinhardt et al., 1990; Niskanen et al., 1991; Houe et al., 1995; Houe, 1999). A $15 \%$ prevalence of dairy herds with persistently infected (PI) animals was recently reported in New Zealand (Thobokwe et al., 2004). Infection may be subclinical in many instances. Exposure of naïve pregnant animals to BVDV can lead to early embryo or fetal mortality, abortion, mummification, PI animals (that may subsequently die from mucosal disease), and calves with congenital defects, poor growth rates, and increased age at first calving (Valle et al., 2001). The outcome of exposure is dependent upon the stage of gestation when infection occurs (McGowan et al., 1993a; Moening and Leiss, 1995). The economic cost of BVDV can vary greatly from herd to herd depending on the initial herd immunity, strain of infecting virus, and stage of the breeding cycle when infection occurs. At the population level, losses are estimated at US $\$ 10$ to $\$ 57$ million per 1 million calvings (Houe et al., 1993a,b; Houe, 1999).

An initial estimation of BVDV infection status of the herd can be made using a bulk tank milk (BTM) sample (Bitsch and Rønsholt, 1995). Good correlation exists between seroprevalence and BTM antibody concentrations (Niskanen, 1993). A strong association between seroprevalence in the herd and the likelihood of a PI being present has also been demonstrated (Houe and Meyling, 1991). To relate BTM inhibition percentages (\%INH) to the likelihood of the presence of PI animals currently in the herd, spot testing of young stock at 6 to $18 \mathrm{mo}$ of age (after maternal antibodies have waned) provided a reliable indication of current infection and the likely presence of a PI animal in the herd (Houe and Palfi, 1993; Houe, 1994; Bitsch and Rønsholt, 1995). After sampling a subset of young stock in dairy herds, 
receiver operator characteristic (ROC) analysis suggested an optimal cut-off for BTM of $80 \% \mathrm{INH}$, giving $81.2 \%$ sensitivity and $91.2 \%$ specificity for the detection of PI animals in a New Zealand study (Thobokwe et al., 2004).

Several authors have examined reproductive performance in association with BVDV status either at the individual animal level using serum antibody status (Houe et al., 1993a; Larsson et al., 1994; Rüfenacht et al., 2001), or at the herd level using 2 or more BTM samples at intervals of 4 to 18 mo to determine the herd BVDV status (Fredriksen et al., 1998; Valle et al., 2001; Robert et al., 2004). With the exception of an increased risk of abortion, which was most frequently associated with BVDV infection (Larsson et al., 1994; Fredriksen et al., 1998; Rüfenacht et al., 2001), the studies mentioned have given rise to conflicting results. This is not surprising considering the differences in study design, power, classification of BVDV status, and method of analysis. Although a decreased conception rate has been reported (Houe et al., 1993a; Larsson et al., 1994), other studies failed to demonstrate negative effects of BVDV on return rates, number of inseminations per cow, and calving intervals (Fredriksen et al., 1998; Rüfenacht et al., 2001; Valle et al., 2001). Robert et al. (2004) reported an increased risk of late returns ( $>25 \mathrm{~d}$ ) in BVDV-infected herds, but did not observe an association between the rate of 3 -wk returns and herd BVDV status.

The primary aim of this study was to identify potential reproductive and production loss in BVDV-infected herds in New Zealand, as determined by a single BTM sample. This study also aimed to explore the association between BVDV status and cull rate related to infertility, for which data are lacking. Most of the epidemiological studies previously referred to in this introduction were based in Europe. The small size of European study herds (12 to 26 cows) (Rüfenacht et al., 2001; Valle et al., 2001; Robert et al., 2004) and their management (housing, concentrate feeding, less strict seasonal calving) is considerably different from the average dairy herd in New Zealand. The impact of BVDV infection might therefore vary, as might the ability to detect its effects in herds.

\section{MATERIALS AND METHODS}

\section{Herds and Animals}

Data used in this study originated from a study conducted in 2002 to evaluate the predictive value of BVDV antibodies in BTM for 724 dairy herds; data collection methods were described in that article (Thobokwe et al., 2004). Briefly, a simple random sample of 800 herds was targeted from a population of dairy herds in the
North Island of New Zealand. A total of 724 randomly sampled herds was available for BVDV BTM antibody testing in March 2002. To validate the BTM results, they were compared with the BVD herd status based on a spot check of 12-mo-old calves. The earlier study (Thobokwe et al., 2004) compared the antibody status of 15 randomly selected calves from 50 herds with the BTM results, which resulted in a cut-off point of $\geq 80 \%$ INH BVDV antibody in BTM indicating herd infection status. For the current study, information on individual reproductive and milk production performance of cows was available from the Livestock Improvement Corporation (LIC) database (LIC, Private Bag 3016, Hamilton, New Zealand) and was compared with that cut-off point.

\section{Data Validation}

Available herd information from 632 herds (267,171 cows) was downloaded from the LIC database and validated using Access (Microsoft Corp., Redmond, WA). In total, 2,316 cows from 3 herds were initially excluded from the database for the following reasons: 84 cows had duplicate entries (same lifetime identification and same herd code) but were listed with a different exit reason; a further 1,640 cows were allocated to 2 different herds with 2 different results from the bulk tank milk testing; and 592 animals were allocated to 2 different herds at the same time with different BTM test results, and thus were regarded as entry errors.

Only animals with calving dates from June 1, 2001, to March 31, 2003 (590 herds, 185,050 animals) and mating dates from September 1, 2001 to May 31, 2002 (587 herds, 146,038 animals) were included in this study. These periods included the date of BVDV BTM antibody test in March 2002.

\section{Response Variables}

The following variables of interest were calculated as herd-level averages during the 2001-2002 season: annual pregnancy rate, first-service conception rate, calving-to-conception interval, annual abortion rate, overall annual culling rate, annual culling rate because of infertility, proportion physiological service intervals, and milk solids produced per day adjusted for lactation stage and parity.

Pregnancy Rate, First-Service Conception Rate, Calving-to-Conception Interval, Abortion Rate, Induction Rate, and Culling Rate. The calculation of the performance indicators required cows with complete records of calving and mating dates in 2001-2002 as well as calving or removal dates of the subsequent season, 2002-2003. There were 571/590 herds (96.8\%) 
left with complete information to calculate pregnancy rate, first-service conception rate, and calving-to-conception interval, 570/590 herds $(96.6 \%)$ to calculate culling rates, and 565/590 herds $(95.8 \%)$ for abortion and induction rates.

The gestation period was calculated as the difference between the last mating date in the 2001-2002 season and the calving date in the subsequent season. A key was derived that defined the pregnancy status (yes/no), first-service conception (yes/no), and the time between calving and conception for each animal. If no information about the pregnancy outcome was stated in the LIC database, a gestation period of 270 to300 d was considered as "normal," a gestation period of 220 to 269 $\mathrm{d}$ as "induced," and a gestation period of 63 to $219 \mathrm{~d}$ as "abortion."

Cows with those gestation periods were assumed to have conceived after first mating if they only had one mating in that season; otherwise, first-service conception was assumed unsuccessful. In addition to cows with normal gestation periods, a successful first-service conception was recorded for animals in which an induction or abortion was stated in the database and that had a gestation period of $<330 \mathrm{~d}$ or $<250 \mathrm{~d}$, respectively, and only one service. Animals without information about calving dates of the subsequent season were considered nonpregnant if they were culled or sold because of infertility. If any other reason than infertility was stated in the records of such cows, they were excluded from the analysis of first-service conception rates.

The calving-to-conception interval was calculated as the difference between the calving date and the last mating date in the season 2001-2002. For animals with gestation periods longer than $300 \mathrm{~d}$ and no stated pregnancy outcome, we assumed another mating date $21 \mathrm{~d}$ after the recorded mating and calculated the calvingto-conception interval using that date.

Proportion Physiological Service Intervals. Only the interval between the first and second service was considered because later intervals were regarded as unreliable because of possible hormonal treatment or interference with natural services in the later part of the mating period. Cows without repeated service were excluded from this analysis. Finally, 458/590 herds $(79.0 \%)$ had complete herd and mating information to calculate their proportion physiological service intervals.

Service intervals of 18 to 24 and 38 to $46 \mathrm{~d}$ between the first 2 services were defined as physiological, intervals of 25 to 37 or $>46 \mathrm{~d}$ were defined as nonphysiological. Intervals $<18 \mathrm{~d}$ were excluded from the analysis because of the possibility of hormonal treatment or repeated AI within the same, possibly extended, estrus event.
Milk Production and SCC. There were 541/590 $(91.7 \%)$ herds with complete information on milk test data performed from June 2001 through June 2002. A lactation model was developed to compute a milk production parameter that was comparable between herds using Wood's equation (Wood, 1976). The model standardized milk production on $4.5 \%$ milk fat and $3.2 \%$ protein. The model equation was

$$
\operatorname{FPCM}(\mathrm{kg} / \mathrm{d})=\exp ^{\text {intercept }+\mathrm{b} \times \operatorname{lnDIM}+\mathrm{c} \times \mathrm{DIM}+\mathrm{d} \times \text { age }}
$$

where $\mathrm{FPCM}=$ milk volume $\times$ percentage fat $/ 4.5 \times$ percentage protein/3.2; a, b, c, and d were regression coefficients calculated for each herd; ln = natural logarithm; and age was years from birth to test date. Estimated mean values were generated for each herd for a 3-yrold cow being $100 \mathrm{~d}$ in milk (age $=3$, DIM $=100$ ). One herd was excluded because of an unlikely high mean value.

Individual SCC were transformed by natural logarithm and averaged at the herd level.

\section{Statistical Analysis}

Herd BVDV antibody (\%INH) was the main risk variable of interest. For categorical analysis, it was converted to an ordinal scale with $\leq 40 \%$ INH classified as BVDV antibody class 1,41 to $50 \% \mathrm{INH}$ as class 2,51 to $60 \% \mathrm{INH}$ as class 3,61 to $70 \% \mathrm{INH}$ as class 4,71 to $80 \% \mathrm{INH}$ as class 5 , and $>80 \% \mathrm{INH}$ as class 6 . Mean, standard deviation, median, and $95 \%$ confidence intervals were used to describe the response variables.

The relationship between the response of interest and herd BVDV antibody \%INH was assessed using multivariate regression models. Herd size, breed types, and region were included in the model as covariates to control for confounding effects associated with these variables. Average age was excluded because it was likely related to the herd replacement rate, which could be affected by BVDV infection status, and thus absorb some of the variability in the response that was actually associated with BVDV. The model was

$$
\mathrm{Y}=\alpha+\% \mathrm{INH}+\text { Herdsize }+\mathrm{HF}+\mathrm{JF}+\mathrm{CR}+\text { Region }
$$

where $\mathrm{Y}$ was the response variable (pregnancy rate, first-service conception rate, calving-conception interval, abortion rate, induction rate, proportion physiological service intervals, culling rate, standard milk per day, logSCC); $\alpha$ was the intercept; \%INH was either the inhibition percentage or the BVDV antibody class (1 to 6), herdsize was the number of recorded calvings in the season 2001-2002; HF, JF and CR were the proportions of breed type in each herd ( $\mathrm{HF}=$ Holstein- 
Friesian, JF = Jersey-Friesian, CR = crossbreed). Region was a categorical variable for the location of herds (Northland, Bay of Plenty, and Waikato).

Adjusted means (geometric means for SCC) and confidence intervals were computed as least square means (LSM) and compared between each of the 6 groups of BTM antibody against BVDV (\%INH) using the method of Hsu and Nelson (1998) to correct for multiple comparisons in GLM.

For response variables measured as a proportion, herds including less than 30 cows were not included in the calculations for 2 reasons: 1) to adjust for the relatively large uncertainty about mean proportions based on a low group size, and 2) to remove herds with potential selection bias if only a small fraction of cows was included in the mean estimate, inferring that the mean may not be representing the true herd average.

Plots of residuals vs. predicted values of all models were examined for consistency with assumptions for regression analysis; that is, normal distribution and homogeneity of variances. Independence of the study herds with respect to the performance outcomes was examined (ratio of residual Pearson $\chi^{2} /$ degrees of freedom error $>1$ ); models were adjusted for lack of independence using this ratio as a scale parameter (McCullagh and Nelder, 1989).

\section{Partial Budget}

The results of information obtained from the current study population were combined with data from other sources to calculate a partial budget estimate for the production loss of an average dairy cow in a herd with BTM antibody against BVDV of $>80 \% \mathrm{INH}$ compared with $\leq 80 \% \mathrm{INH}$. The result was extrapolated to the entire dairy herd population in New Zealand based on an estimated prevalence of herds with PI animals of $14.6 \%$ (Thobokwe et al., 2004).

The calculations included loss because of extended calving-to-conception intervals $(+2.35 \mathrm{~d})$, a reduction in milk solids production $(-0.074 \mathrm{~kg} / \mathrm{d}$ for $250 \mathrm{~d})$ adjusted for less pasture use equivalent to the proportion of lost production, an increase in the annual abortion rate $(+2.03 \%)$, reduced survival to $24 \mathrm{mo}$, and increased replacement rate of PI calves with unobserved BVDV infection (Voges, 2006). Values of milk solids and livestock at different ages and production status were sourced from various industry Web sites (http://www.agridata.co.nz/calf-bobby.asp; http:// www.agridata.co.nz/cow-dairy.asp; http://www.agridata.co.nz/Feed.asp; www.ifcndairy.org/specialstudies/ 2005/2005-07.pdf). The price of a replacement heifer $(\$ 1,200)$ was discounted by the average value of a cull cow (\$324). The value of a calf at $100 \mathrm{~kg}$ was discounted by the daily grazing cost for calves ( $\$ 0.9 / \mathrm{d}$ for $120 \mathrm{~d}$ ), setting other maintenance costs to $\$ 0.1 / \mathrm{d}$. The cost of nonproductive pasture days by nonpregnant, dry cows was assumed to be 120 dry-days $\times \$ 2.4 / \mathrm{d} \times 2.03 \%$ extra abortions. The cost of larger induction rates on affected farms was calculated as half the net benefit of calves at $100 \mathrm{~kg}$ of BW, assuming that half of all inductions would lead to a calf born dead.

The calculations included a proportion of $1.33 \%$ PI calves in an average affected herd (Voges, 2006). This estimate was derived from a cohort of 904 reared heifers from 300 herds, 12 of which were PI. In seasonal mating herds (about 92\% of New Zealand herds), the real proportion of PI in an affected herd will often be much larger if susceptible cows are exposed to PI animals during the mating period of approximately 2 mo. The percentage PI in affected herds therefore varied from 1 to $10 \%$ in a sensitivity analysis. The calculation of loss among PI animals included shorter survival up to $2 \mathrm{yr}$ of age and a 5.6-times increased culling rate of PI cows entering the lactating herd (Voges, 2006).

Not considered in the loss estimate was additional health cost because of disease in calves and adult cows (Fourichon et al., 2005).

To include uncertainty in the calculation of the partial budget estimate caused by the cumulative variation of all input parameters, a stochastic simulation using Latin Hypercube sampling with 10,000 iterations was performed in @Risk (Palisade Corporation, 2005). Uncertainty about the input variables was specified as standard deviation for normally distributed variables and as minimum, most likely, and maximum values for variables assumed to be pert-distributed. The result was displayed as a cumulative distribution and 5 th to 95th percentile of the average annual loss per 251-cow herd. Moreover, standard regression coefficients were computed from a multifactorial regression of the outcome (annual loss per herd) on all input variables to compare the relative impact of these variables on the loss estimate (sensitivity analysis).

\section{RESULTS}

\section{Descriptive Results}

The number of herds excluded from the analysis was largest for the rate of physiological service intervals (132/590, 21.0\%); for all other variables, more than $88 \%$ of herds were included. The number of herds, range of herd size, and descriptive statistics of all response variables are shown in Table 1 . Half of all herds did not report any abortions and half did not report any inductions (indicated by a median of zero).

Most response variables were normally distributed, as indicated by means and medians being very similar 
Table 1. Herd averages of reproductive and production performance indicators in a sample of 590 randomly selected dairy herds from Northland, Waikato, and Bay of Plenty, New Zealand

\begin{tabular}{|c|c|c|c|c|c|}
\hline Response variables & $\begin{array}{l}\text { Herds, } \\
\mathrm{n}\end{array}$ & Mean & $\mathrm{SD}$ & Median & $95 \% \mathrm{CI}^{1}$ \\
\hline Rate of physiological service intervals ${ }^{2}(\%)$ & 458 & 91.12 & 5.77 & 91.54 & $90.59-91.65$ \\
\hline First-service conception rate $(\%)$ & 546 & 53.1 & 10.5 & 53.8 & $52.2-54.0$ \\
\hline Number of services per conception & 565 & 1.40 & 0.24 & 1.37 & $1.38-1.42$ \\
\hline Calving-to-conception interval (d) & 518 & 87.7 & 6.6 & 87.2 & $87.1-88.2$ \\
\hline Annual pregnancy rate $(\%)$ & 538 & 93.8 & 4.5 & 94.2 & $93.4-94.2$ \\
\hline Annual abortion rate $(\%)$ & 552 & 2.58 & 8.18 & 0.00 & $1.89-3.27$ \\
\hline Annual induction rate $(\%)$ & 559 & 0.19 & 0.99 & 0.00 & $0.10-0.27$ \\
\hline Annual culling rate (nonconception) (\%) & 557 & 9.1 & 6.4 & 8.5 & $8.5-9.6$ \\
\hline Overall annual culling rate $(\%)$ & 558 & 23.1 & 9.9 & 24.5 & $22.3-23.9$ \\
\hline Geometric mean $\mathrm{SCC}^{3}$ & 534 & 51.9 & NA & 52.1 & $46.9-57.4$ \\
\hline Average milk production ${ }^{4}(\mathrm{~kg} / \mathrm{d})$ & 522 & 17.3 & 2.9 & 17.3 & $17.0-17.5$ \\
\hline
\end{tabular}

${ }^{1} \mathrm{CI}=$ confidence interval.

${ }^{2}$ Insemination dates were unavailable from a significant number of large herds.

${ }^{3}$ Geometric mean adjusted for age and DIM $\times 1,000$.

${ }^{4}$ Adjusted for age, DIM, and $4.5 \%$ fat and $3.2 \%$ protein.

(Table 1). Even though the annual rates of abortion and induction were obviously not normally distributed, the model residuals had a normal distribution and their variances were homogeneous across the range of predicted values.

\section{Association Between Production Loss and BTM Antibody Concentration}

Least square means $( \pm \mathrm{SE})$ for each of the $6 \mathrm{BVDV}$ BTM antibody classes adjusted for herd size, region, and breed composition are shown in Table 2. Not all performance indicators were associated with the concentration of BVDV antibody in BTM. For example, the first-service conception rate, the rate of physiological service intervals, the number of services per conception, the annual pregnancy rate, the geometric herd average SCC, the overall culling rate, and the culling rate on account of conception failure were not associated.

The time from calving to conception, however, increased significantly leading to an approximate increase of 2.35 (SEM 0.88) d to conception (Figure 1). This was calculated as the mean for herds with $>80 \% \mathrm{INH}$ minus the mean for all other groups. Abortion rates were $1.63 \%$ (SE $0.76 \%$ ) to $1.85 \%$ (SE $0.85 \%$ ) when the concentration of BVDV antibody in BTM was $\leq 60 \% \mathrm{INH}$ and $3.36 \%$ (SE $1.02 \%$ ) to $4.42 \%$ (SE $0.80 \%$ ) when $>60 \% \mathrm{INH}$ (Table 2). This cut-off point for \%INH

Table 2. Adjusted means \pm SE for each response variable within bovine viral diarrhea virus (BVDV) bulk tank milk (BTM) antibody class

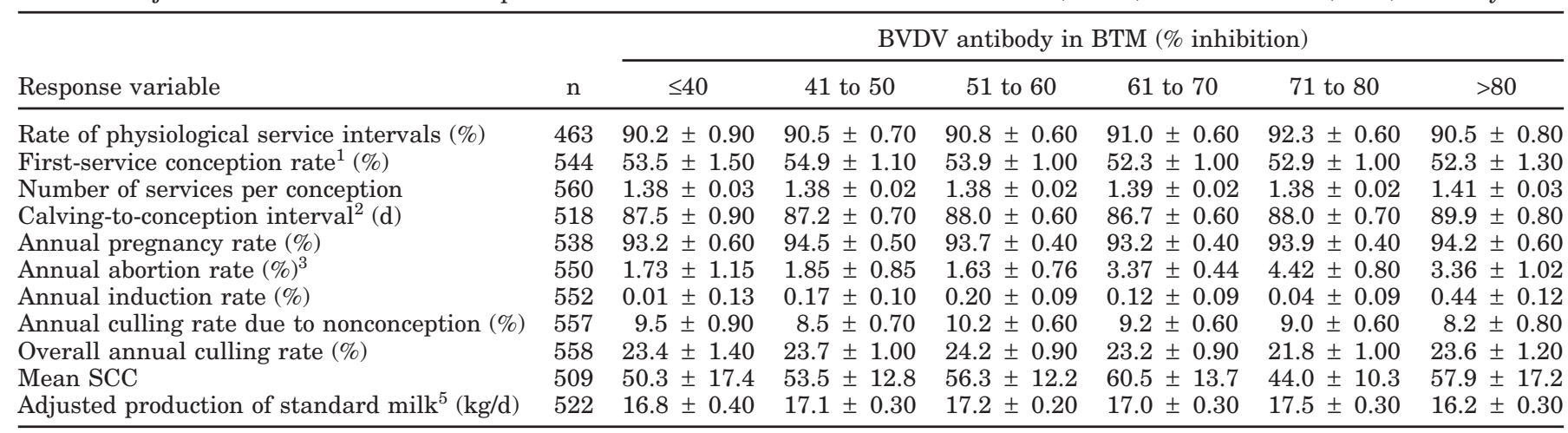

${ }^{1}$ Group $41-50 \% \mathrm{INH}$ tended to have a greater first-service conception rate than group $61-70 \% \mathrm{INH}(P=0.07)$ and group $>80 \% \mathrm{INH} ; P=$ $0.12)$.

${ }^{2}$ Group $>80 \% \mathrm{INH}$ had significantly longer calving-to-conception intervals than groups $\leq 40 \% \mathrm{INH}(P=0.05), 41-50 \% \mathrm{INH}(\mathrm{P}=0.01), 51-$ $60 \% \mathrm{INH}(P=0.07), 61-70 \% \mathrm{INH}(P=0.003)$, and $71-80 \% \mathrm{INH}(P=0.08)$.

${ }^{3}$ Group $>60 \% \mathrm{INH}$ had, on average, $2.03 \%$ higher abortion rates than the average of groups $\leq 60 \% \mathrm{INH}(P=0.004)$.

${ }^{4}$ Least squares mean + difference to upper $95 \%$ confidence limit of the geometric mean.

${ }^{5}$ Adjusted for DIM and $4.5 \%$ fat and $3.2 \%$ protein; production in group $>80 \% \mathrm{INH}$ was, on average, $1 \mathrm{~kg} / \mathrm{d}$ lower than each mean of groups $41-70 \%$ INH $(P<0.05)$. 


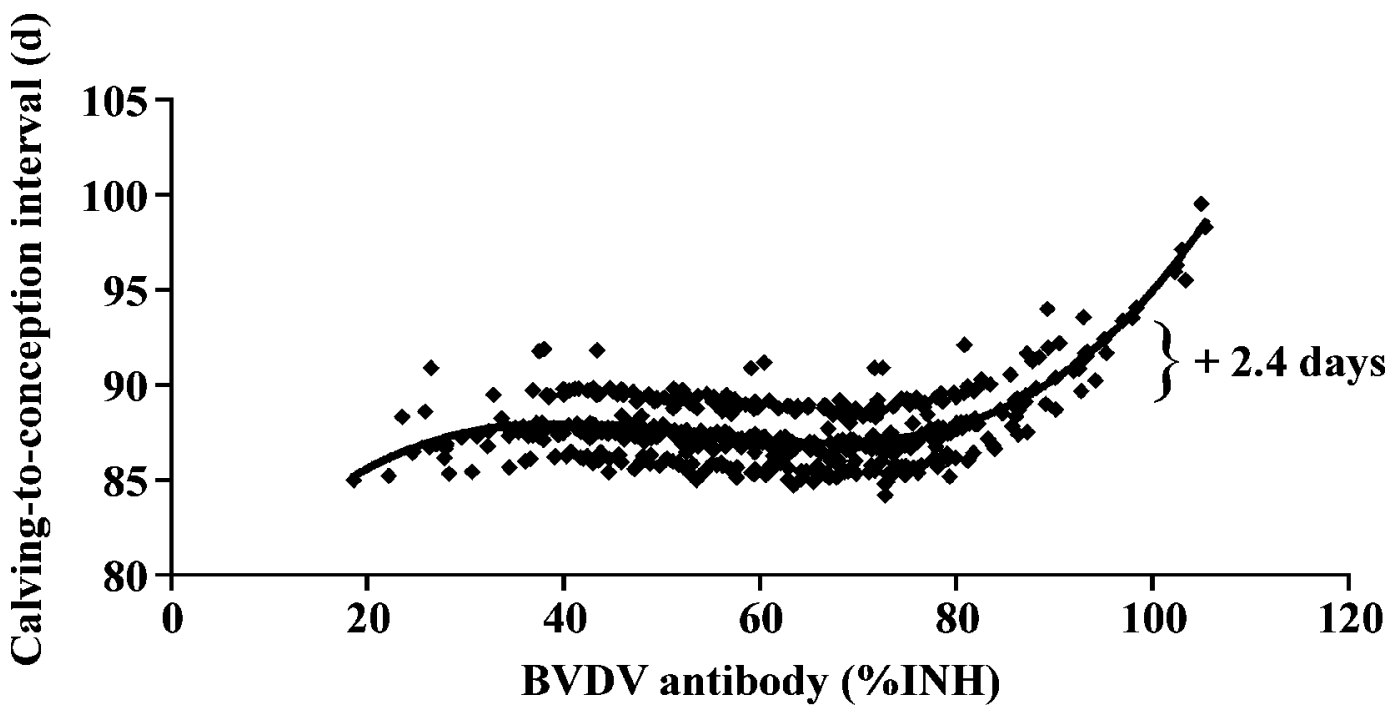

Figure 1. Interval from calving to conception in relation to percentage inhibition of bovine viral diarrhea virus (BVDV) antibody (\% inhibition, \% INH) in bulk tank milk (estimated values with polynomial trendline) adjusted for herd size, region, and breed composition (518 randomly selected herds).

was therefore chosen to estimate the effect of BVDV on abortion but only considered for herds with BTM antibody $>80 \% \mathrm{INH}$ in the partial budget. The increase in the high BTM antibody group was $2.03 \%$ (SE $0.69 \%$ ). The rate of inductions, which were reported to LIC, was substantially larger $(0.44 \%$; SE $0.12 \%)$ in highly exposed farms $(>80 \% \mathrm{INH})$ than in all other farms $(0.12 \%$; SE $0.05 \%)$. The fact that overall induction rates were generally low was very likely caused by a low reporting rate.

Milk production was $0.99 \mathrm{~kg} / \mathrm{d}$ (SE $0.34 \mathrm{~kg} / \mathrm{d}$ ) less in herds with $>80 \%$ INH of BVDV antibody in BTM than in herds with $\leq 80 \% \mathrm{INH}$ (Figure 2 ). This was equivalent to $0.074 \mathrm{~kg}$ of milk solids per day and $5.8 \%$ of total production.

\section{Partial Budget}

Table 3 translates the adverse effects of a high BVDV antibody concentration in BTM observed in this study to gross economic loss in affected herds ( $>80 \%$ INH vs. $\leq 80 \% \mathrm{INH}$ ) and extrapolates this estimate to the level of the dairy industry of New Zealand. For an average herd with 251 cows, the largest annual loss component in affected herds was the decline in milk production (NZ\$10,516), followed by increased abortions (NZ\$5,935), increased time to conception (NZ\$3,369), loss among PI animals (NZ\$1,660), and calf loss as a consequence of abortion or induction (NZ\$441). This summed to a total annual loss of about NZ $\$ 21,921$ per year for a herd with 251 cows affected by BVDV, with a $90 \%$ credible interval of $\mathrm{NZ} \$ 17,959$ to $\mathrm{NZ} \$ 29,666$ (Fig- ure 3 ). Given that $14.6 \%$ of all herds in the 3 study regions had BVDV antibody concentrations of $>80 \% \mathrm{INH}$, and if it is assumed that this is similar in all regions of New Zealand, the estimated loss to the dairy industry in New Zealand amounts to approximately NZ $\$ 44.5$ million every year (credible interval of $\mathrm{NZ} \$ 32.3$ to NZ\$65.1 million).

Not surprisingly, the proportion of highly exposed herds in the population ( $>80 \% \mathrm{INH})$ had the strongest impact on total industry loss. The sensitivity analysis, however, also revealed that the proportion of PI animals in an affected herd was the factor with the second highest impact on total loss (Table 4). This was related to the large uncertainty (1 to 10\%) assumed for this variable for reasons mentioned previously. A change in the proportion PI from 1.3 to $2.7 \%$ increased the total loss by $7 \%$. In order of relative impact, the proportion PI was followed by the farmgate price for milk solids, the effect of BVDV exposure on milk production, increased abortions, herd average milk production, the cost per pasture-day, and the cost of replacement heifers. All other factors had relatively little impact on the loss estimate.

\section{DISCUSSION}

This study derives its strength from the inclusion of a large number of randomly selected herds representative of dairy producers in the Waikato, Bay of Plenty, and Northland regions of New Zealand. Assuming that the BVDV prevalence is similar in other regions, the results may be valid for the entire country. Herd aver- 


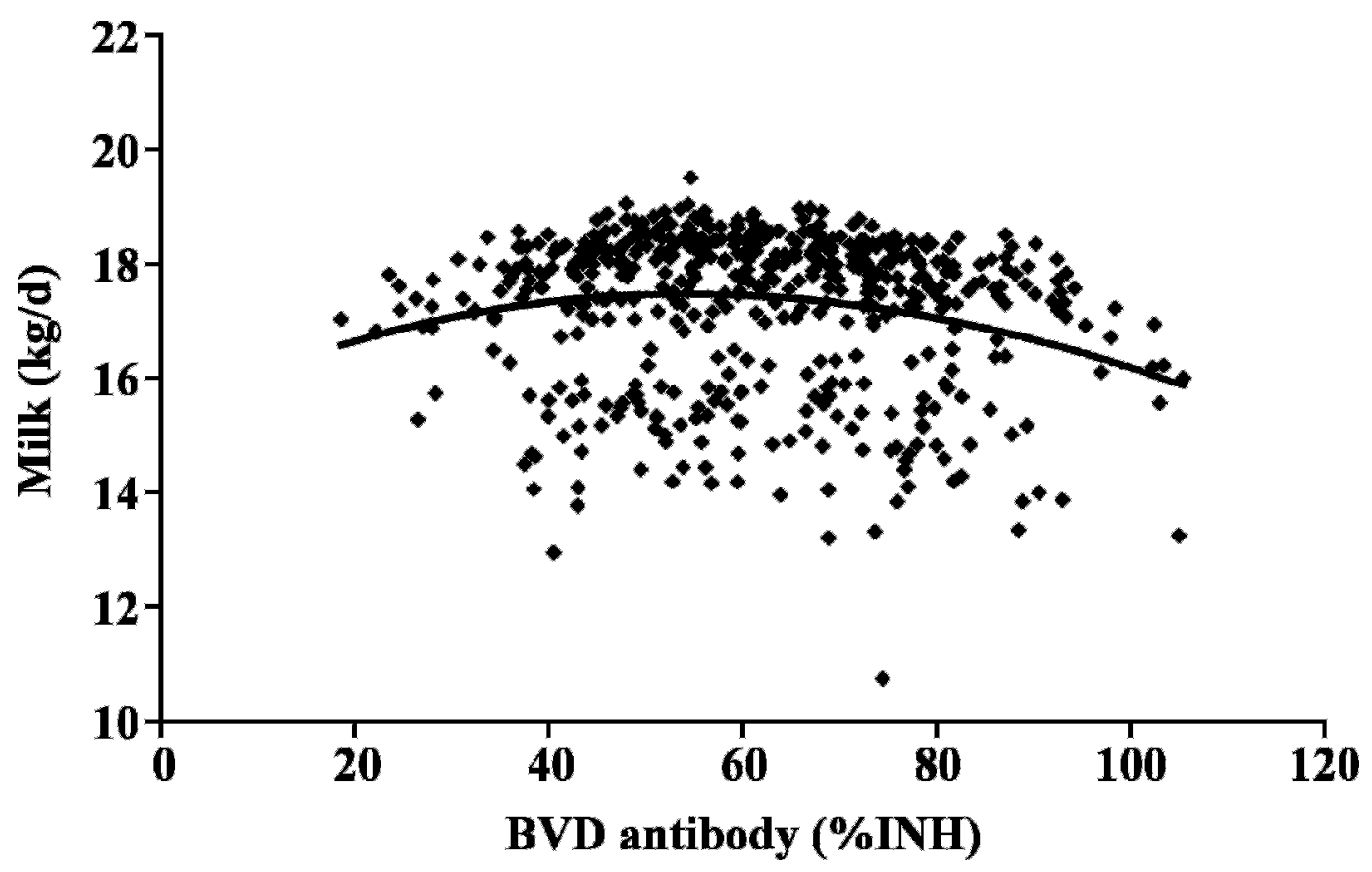

Figure 2. Herd average production (dots + polynomial trend line) of solids-adjusted milk (kg/d) of 522 dairy herds by increasing (BVDV) antibody (\% inhibition, \% INH) in bulk tank milk.

ages shown in Table 1 may be regarded as typical for the New Zealand dairy industry. Reporting bias may have existed, however, because the data were extracted from the LIC database. The bias may particularly affect abortion and induction rates because farmers are unlikely to observe and report such events accurately.
Induction rates in particular were far below expectation. Abortion rates, however, were mainly derived from the presence or absence of dates of subsequent calving, and the mean rate of $2.6 \%$ was similar to that in an earlier report (Thobokwe and Heuer, 2004). Although the reported induction rates may be grossly underesti-

Table 3. Partial budget for the estimated loss for an affected herd and for the New Zealand dairy population ${ }^{1}$

\begin{tabular}{|c|c|c|}
\hline Economic trait & Calculation $^{3}$ & Cost $(\mathrm{NZ} \$)$ \\
\hline Fertility loss & $2.4 \mathrm{~d} /$ cow to conception $\times 1.37 \mathrm{~kg}$ of solids $/ \mathrm{d} \times \$ 4.05 / \mathrm{kg}$ of milk solids $\times 251$ cows & 3,369 \\
\hline Production loss & $0.0736 \mathrm{~kg}$ of solids $\times 250$-d lactation $\times \$ 4.05 \times 251$ cows & 18,705 \\
\hline Saved pasture & $5.4 \%$ lost production $\times 250 \mathrm{~d}$ on pasture $\times \$ 2.4$ /pasture-day $\times 251$ cows & $(-) 8,189$ \\
\hline Calf & $2.03 \%$ calves aborted $\times \$ 80$ net calf value $\times 251$ cows & 407 \\
\hline Induction & $\begin{array}{l}0.33 \% \text { extra induction } \times 50 \% \text { calf loss } \times \$ 80 \text { net calf value (rev-cost at } 100 \mathrm{~kg} \\
\text { of } \mathrm{BW}) \times 251 \text { cows }\end{array}$ & 34 \\
\hline Extra culling & $\begin{array}{l}1.33 \% \mathrm{PI} \times 75 \% \text { survival to } 2 \mathrm{yr} \times 69 \% \text { extra cull rate } \times \$ 876 \text { cow replacement } \\
\times 251 \text { cows }\end{array}$ & 1,527 \\
\hline Annual loss (affected herd) & Sum of component cost & 21,921 \\
\hline Annual loss per cow (affected herd) & $\$ 21,921 / 251$ & 87 \\
\hline Prevalence of affected herds ${ }^{2}$ & 0.146 & \\
\hline Herds affected & $13,892 \times 0.146=2,028$ & \\
\hline Annual loss (any herd) & $\$ 21,921 \times 0.146$ & 3,200 \\
\hline
\end{tabular}

\footnotetext{
${ }^{1}$ Assuming $251 \mathrm{cows} / \mathrm{herd}, 13,892 \mathrm{herds}, 1.36 \mathrm{~kg}$ of milk solids/cow per day sold for $\$ 4.05$ per kg; Livestock Improvement Corporation
} dairy statistics 2000-2001.

${ }^{2}$ Thobokwe et al. (2004).

${ }^{3}$ Differences between calculations and results are due to rounding errors. 


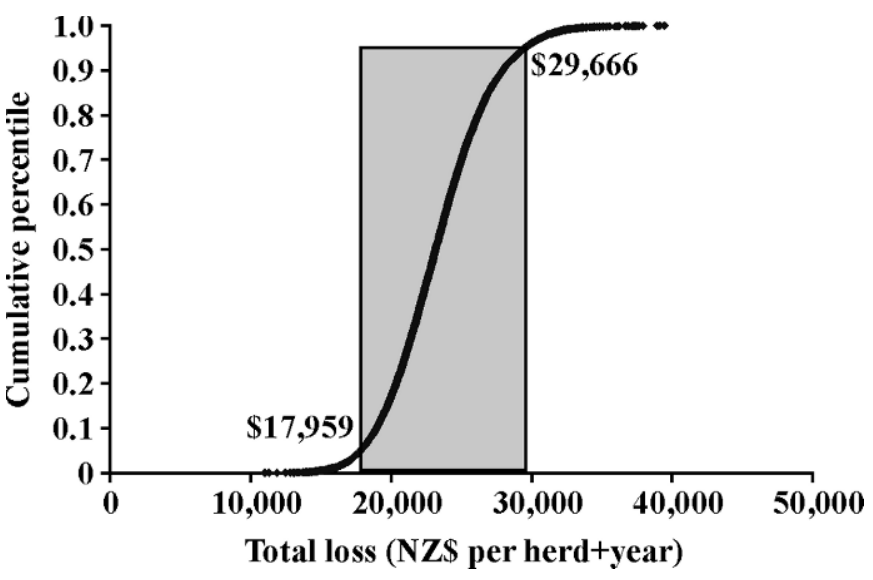

Figure 3. Cumulative distribution (line) and 90\% credible interval of 10,000 simulations (box) of the estimated annual loss of an affected herd ( 251 cows) due to high exposure to BVDV.

mated, it was unlikely that the rate of underreporting correlated with BTM antibody to BVDV; hence, we believe that the observed association between induction rates and BTM antibody to BVDV was valid.

Using herd averages for both, the extent of exposure to BVDV and performance parameters combined with estimated economic loss requires that the implied causal associations observed at the herd level were also true at the animal level. The analysis of this study used data from observations at the herd level, thus we cannot prove that the same associations existed at animal level. The same constraint applies to several studies in which the BVDV status and the economic response have also been defined at the herd level (Fredriksen et al., 1998; Valle et al., 2001; Robert et al., 2004). As long as the BVDV status is defined at the herd level, any analysis may be prone to ecologic fallacy; that is, the inference from group- to individual-level associations. The benefit of carrying out analysis at the herd level, however, is that data can be obtained from a subset of the reference population thus allowing inference for the dairy industry at reasonable cost. Because it was the primary objective of this study to estimate industry-wide losses associated with BVDV in dairy herds in New Zealand, we decided to use a herd-level analysis to provide initial estimates of loss associated with BVDV to be refined by animal-level investigations later. We believe that our results were especially credible for those response variables that showed a trend effect of decreasing performance with increasing BTM \%INH.

The results clearly showed that the BVDV antibody concentrations of BTM correlated with reproductive and production performance, and these associations have also been shown to exist at animal level by other workers mentioned earlier. Thus, it seems highly un-

Table 4. Means and assumed variability of partial budget components and result of the sensitivity analysis estimating the relative impact (standardized regression coefficient) of economic loss for the dairy industry due to exposure to bovine viral diarrhea virus (BVDV) indicated by $>80 \%$ inhibition $(\% \mathrm{INH})$ in bulk tank milk (regression $\mathrm{R}^{2}=0.98$ )

\begin{tabular}{|c|c|c|c|c|c|c|c|}
\hline Partial budget component & Distribution & Mean & SD & Minimum & $\begin{array}{l}\text { Most } \\
\text { likely }\end{array}$ & Maximum & $\begin{array}{l}\text { Standardized } \\
\text { regression } \\
\text { coefficient }\end{array}$ \\
\hline Prevalence of herds $>80 \%$ INH BVDV antibody & Pert & & & 0.090 & 0.146 & 0.200 & 0.681 \\
\hline Farmgate price/kg of milk solid (NZ\$) & Normal & 4.05 & 0.25 & & & & 0.278 \\
\hline Production loss (kg of solids/cow per d) & Pert & & & 0.050 & 0.074 & 0.097 & 0.257 \\
\hline Extra abortion incidence (\%) & Pert & & & 1.000 & 2.024 & 3.060 & 0.247 \\
\hline Average lactation length (d) & Normal & 250 & 20 & & & & 0.170 \\
\hline Extra pasture days of aborting cows (d) & Normal & 120 & 40 & & & & 0.103 \\
\hline Revenue per cull cow $(\mathrm{NZ} \$)$ & Normal & 324 & 32 & & & & -0.057 \\
\hline Survival of PI animals to $24 \mathrm{mo}$ & Pert & & & 0.500 & 0.750 & 1.000 & 0.056 \\
\hline Cull rate of PI cows & Pert & & & 0.700 & 0.844 & 1.000 & 0.052 \\
\hline Increased calving to conception interval (d) & Pert & & & 2.000 & 2.420 & 2.840 & 0.047 \\
\hline Solids in standard milk (\%) & Normal & 8.00 & 0.50 & & & & 0 \\
\hline Rearing cost for a replacement heifer (NZ\$) & Normal & 302 & 30 & & & & 0 \\
\hline Culling rate of normal cows ${ }^{1}$ & Pert & & & 0.060 & 0.080 & 0.100 & 0 \\
\hline Culling rate $\mathrm{PI}^{1}$ & Pert & & & 0.400 & 0.450 & 0.500 & 0 \\
\hline Extra induction incidence $(\%)$ & Pert & & & 0.100 & 0.332 & 1.000 & 0 \\
\hline
\end{tabular}

${ }^{1}$ Voges, 2006. 
likely that a strong ecologic fallacy biased the results of this study. The group of herds with $>80 \%$ INH exhibited poor performance. This was the group that showed a close relationship between BTM antibody and antibody prevalence in calf mobs (i.e., spot-check) with $81 \%$ sensitivity and $91 \%$ specificity (Thobokwe et al., 2004). The spot-check is a recognized method to determine whether one or more PI animals are likely to be present in the milking herd (Houe and Palfi, 1993; Houe, 1994; Bitsch and Rønsholt, 1995). Nevertheless, misclassification of the BVDV herd status based on a single antibody test in BTM remained a concern. At a relatively low prevalence of actively infected herds, the consequence of a BTM test with the given sensitivity and specificity would be an overestimate of true herd prevalence. This bias, however, was probably small and, combined with a likely underestimate of the economic effects (e.g., attributable to excluding effects of BVDV on clinical disease incidence), the resulting bias on economic consequences of BVDV at population level was probably very small.

The rate of physiological service intervals was analyzed because BVDV is known to cause early embryonic death leading to a return to estrus (McGowan et al., 1993b), but our data did not show an association with BVDV antibody in BTM, possibly because such an effect was too rare to be significant at the population level. The first-service conception rate was expected to decrease with increasing BVDV antibody because in vivo studies have demonstrated fertilization failure to be a primary cause of reduced conception rates (Grahn et al., 1984). We did not observe this effect, possibly because of the small proportion of the herd being infected at the time of fertilization. The annual pregnancy rate is the result of reproductive performance and culling, and it involves repeat breeding. All of these factors contribute to the final reproductive outcome; thus, a BVDV effect was unlikely associated significantly with the overall annual pregnancy rate. Similarly, culling rates were unaffected because only about $40 \%$ of the cull cows were removed due to reproductive failure. Similarly, crude culling risk was not increased in BVDV-infected herds in Norway (Valle et al., 2001). Immune suppression leading to decreased neutrophil function in periparturient disorders such as mastitis in cows (Cai et al., 1994) was hypothesized, but not substantiated, by the data. In earlier studies, increasing or persistently high bulktank BVDV status has been associated with an increased incidence of clinical mastitis, although no effect on SCC was observed in this or earlier studies (Niskanen et al., 1995; Waage, 2000).

The time from calving to conception increased probably because of fertilization failure and embryo loss (Grahn et al., 1984; McGowan et al., 1993a). We ob- served increased abortion rates when BVDV antibody concentrations were greater than $60 \%$ INH. Other studies also found an increased number of abortions in herds experiencing natural infection with BVDV (Barber et al., 1985; Roeder et al., 1986; Larsson et al., 1994). Moreover, abortions could be induced by experimental infection (Casaro et al., 1971; Done et al., 1980). The association between herd-level BVDV infection status and abortion rates was therefore not surprising. A delay in conception may explain why induction rates were substantially larger in herds with $>80 \% \mathrm{INH}$ of BVDV antibody in BTM.

A sudden reduction in milk yield has been described from individual herd disease outbreaks (Barber et al., 1985; Larsson et al., 1994). Moerman et al. (1994) found a significant reduction in milk yield experienced in cows seroconverting to BVDV compared with herd mates that did not seroconvert. Thus, immune suppression followed by an increase in clinical mastitis (Cai et al., 1994) and feed energy used for immune function (both initiated by BVDV infection) were plausible causes to explain the observed decline in milk production.

Information on mating dates was scantier than other performance data and missing from many large herds. Thus, the estimate of $91.2 \%$ physiological service intervals with a standard deviation of $5.7 \%$ may be valid for herds with up to 500 cows. The estimated 1.40 (SE 0.24) services per conception was probably an underestimate of the true number of services because more (natural) services will have occurred than are captured in the database. The mean induction rate was likely underestimated, because herd owners might have been reluctant to report the true number of induced cows to LIC. All other performance indicators and their standard deviations seemed to be reasonable estimates for dairy herds in the 3 study regions.

The final loss estimate based on the partial budget approach was probably conservative because, first, it did not include increased incidence of clinical disease such as calf disease, mastitis, or retained placenta (Larsson et al., 1994; Niskanen et al., 1995). In French dairy herds, the inclusion of disease in a partial budget increased the loss estimates by 10 to $16 \%$ (Fourichon et al., 2005). The generally smaller disease incidence in New Zealand dairy herds may not affect our estimates greatly, but including disease would certainly increase the estimate of loss. Second, the sensitivity analysis showed that the proportion of PI animals in the herd had a substantial effect on economic loss based on the particular uncertainty about this parameter. This was substantiated by case reports of $>10 \%$ PI heifers in a herd (Ellison et al., 2005; Thompson, 2005). Third, misclassification may have included a number of noninfected herds in the exposed group (>80\% INH) and in- 
fected herds in the nonexposed group ( 0 to $80 \% \mathrm{INH}$ ). This would reduce the true difference between infected and noninfected herds. We therefore believe that the total loss of NZ $\$ 44.5$ million per 3.48 million dairy cows, equivalent to NZ $\$ 13.7$ million per 1 million calvings, may be an underestimate. It is certainly in the lower range of loss estimated for the US; that is, US $\$ 10$ to US\$57 million (Houe et al., 1993a,b; Houe, 1999).

The 2 factors with the greatest impact on this estimate (also the factors about which no reliable information exists to date) were the true prevalence of herds with an active infection and the proportion of PI heifers and cows in the lactating herd. A $1 \%$ increase in the proportion PI was associated with NZ\$1.55-milliongreater loss at the population level; thus, valid estimates of the proportion PI in infected herds would have substantial impact on the accuracy of total loss.

\section{CONCLUSIONS}

Bovine viral diarrhea virus contributed significantly and substantially to economic loss of dairy herds in New Zealand in the regions Northland, Waikato, and Bay of Plenty, attributable to increased abortion rates, extended calving-to-conception intervals, and reduced milk production. This effect is likely to be similar in other regions of New Zealand. Combining uncertainty of all input parameters, the partial budget for annual economic loss of New Zealand dairy farmers resulted in a conservative estimate of NZ $\$ 32.3$ to NZ $\$ 65.1$ million, with a mean of NZ $\$ 44.5$ million. The estimate was highly dependent on the prevalence of affected herds and the proportion of PI animals in the lactating herd; thus, these parameters require more investigation.

\section{ACKNOWLEDGMENTS}

The authors would like to express their gratitude to Dairy Insight (New Zealand) for funding the study, and to Livestock Improvement Corporation Ltd. (Hamilton, New Zealand) for logistical support and the facilitation of milk sampling.

\section{REFERENCES}

Barber, D. M., P. F. Nettleton, and J. A. Herring. 1985. Disease in a dairy herd associated with the introduction and spread of bovine virus diarrhoea virus. Vet. Rec. 117:459-464.

Bitsch, V., and L. Rønsholt. 1995. Control of bovine viral diarrhea virus infection without vaccines. Vet. Clin. Food Anim. 11:627640.

Cai, T. Q., P. G. Weston, L. A. Lund, B. Brodie, D. J. McKenna, and W. C. Wagner. 1994. Association between neutrophil functions and periparturient disorders in cows. Am. J. Vet. Res. 55:934-943.

Casaro, A. P. E., J. W. Kendrick, and P. C. Kennedy. 1971. Response of the bovine fetus to bovine viral diarrhoea-mucosal disease virus. Am. J. Vet. Res. 32:1543-1561.
Done, J. T., S. Terlecki, C. Richardson, J. W. Harkness, J. J. Sands, D. S. P. Patterson, D. Sweasey, I. G. Shaw, C. E. Winkler, and S. J. Duffell. 1980. Bovine viral diarrhoea-mucosal disease virus: Pathogenicity for the fetal calf following maternal infection. Vet. Rec. 106:473-479.

Ellison, R. S., R. Hermans, M. Clemance, and J. Voogt. 2005. BVD disasters - They do occur. Vetscript 18:30-31.

Fourichon, C., F. Beaudeau, N. Bareille, and H. Seegers. 2005. Quantification of economic losses consecutive to infection of a dairy herd with bovine viral diarrhoea virus. Prev. Vet. Med. 72:177-181.

Fredriksen, B., S. A. Ødegaard, and T. Løken. 1998. The effect of bovine virus diarrhoea virus on reproduction in recently infected Norwegian dairy herds. Acta Vet. Scand. 39:99-108.

Grahn, T. C., M. L. Fahning, and R. Zemjanis. 1984. Nature of early reproductive failure caused by bovine virus diarrhoea virus. J. Am. Vet. Med. Assoc. 185:429-432.

Houe, H. 1994. Bovine virus diarrhoea virus: Detection of Danish dairy herds with persistently infected animals by means of a screening test of ten young stock. Prev. Vet. Med. 19:241-248.

Houe, H. 1999. Epidemiological features and economical importance of bovine virus diarrhoea virus (BVDV) infections. Vet. Microbiol. 64:89-107.

Houe, H., J. C. Baker, R. K. Maes, J. W. Lloyd, and C. Enevoldsen. 1995. Comparison of the prevalence and incidence of infection with bovine viral diarrhoea virus (BVDV) in Denmark and Michigan and association with possible risk factors. Acta Vet. Scand. 36:521-531.

Houe, H., and A. Meyling. 1991. Prevalence of bovine virus diarrhoea (BVD) in 19 Danish herds and estimation of incidence of infection in early pregnancy. Prev. Vet. Med. 11:9-16.

Houe, H., and V. Palfi. 1993. Estimation of herd incidence of infection with bovine viral diarrhoea virus (BVDV) in herds previously without animals persistently infected with BVDV. Acta Vet. Scand. 34:133-137.

Houe, H., K. M. Pedersen, and A. Meyling. 1993a. The effect of bovine virus diarrhoea virus (BVDV) infection on conception rate. Prev. Vet. Med. 15:117-123.

Houe, H., K. M. Pedersen, and A. Meyling. 1993b. A computerised spread sheet model for calculating total annual national losses due to bovine viral diarrhoea virus infection in dairy herds and sensitivity analysis of selected parameters. Pages 179-184 in Proc. 2nd Symp. Pestiviruses, Annecy, France. Eur. Soc. Vet. Virol.

Hsu, J. C., and B. Nelson. 1998. Multiple comparisons in the general linear model. J. Comput. Graph. Stat. 7:23-41.

Larsson, B., R. Niskanen, and S. Alenius. 1994. Natural infection with bovine virus diarrhoea virus in a dairy herd: A spectrum of symptoms including early reproductive failure and retained placenta. Anim. Reprod. Sci. 36:37-48.

McCullagh, P., and J. A. Nelder. 1989. Generalized Linear Models. Chapman \& Hall, London, UK.

McGowan, M. R., P. D. Kirkland, S. G. Richards, and I. R. Littlejohns. 1993a. Increased reproductive losses in cattle infected with bovine pestivirus around the time of insemination. Vet. Rec. 133:39-43.

McGowan, M. R., P. D. Kirkland, B. J. Rodwell, D. R. Kerr, and C. L. Carroll. 1993b. A field investigation of the effects of bovine viral diarrhoea virus infection around the time of insemination on the reproductive performance of cattle. Theriogenology 39:443-449.

Moening, V., and B. Leiss. 1995. Pathogenesis of intrauterine infections with bovine viral diarrhoea virus. Vet. Clin. Food Anim. 11:477-488.

Moerman, A., P. J. Straver, M. C. de Long, J. Quak, T. Baanvinger, and J. T. van Oirschot. 1994. Clinical consequences of a bovine virus diarrhoea virus infection in a dairy herd: A longitudinal study. Vet. Q. 16:115-119.

Niskanen, R. 1993. Relationship between antibodies to bovine viral diarrhoea virus in bulk tank milk and the prevalence of cows exposed to the virus. Vet. Rec. 133:341-344.

Niskanen, R., S. Alenius, B. Larsson, and S.-O. Jacobsson. 1991. The determination of antibodies to bovine viral diarrhoea virus (BVDV) in bulk tank milk as a tool in the diagnosis and prophy- 
laxis of BVDV infections in dairy herds. Arch. Virol. Suppl. 3:245-251.

Niskanen, R., U. Emanuelson, J. Sundberg, B. Larsson, and S. Alenius. 1995. Effects of infection with bovine virus diarrhoea virus on health and reproductive performance in 213 dairy herds in one county in Sweden. Prev. Vet. Med. 23:229-237.

Palisade Corporation. 2005. Version 4.5.5 Professional Edition. Palisade Corp., Ithaca, NY.

Reinhardt, G., S. Riedemann, S. Ernst, M. Aguilar, R. Enriquez, and J. Gallardo. 1990. Seroprevalence of bovine viral diarrhoea/ mucosal disease in southern Chile. Prev. Vet. Med. 10:73-78.

Robert, A., F. Beaudeau, H. Seegers, A. Joly, and J. M. Philipot. 2004. Large scale assessment of the effect associated with bovine viral diarrhoea virus infection on fertility of dairy cows in 6149 herds in Brittany (Western France). Theriogenology 61:117-127.

Roeder, P. L., M. Jeffrey, and M. P. Cranwell. 1986. Pestivirus fetopathogenicity in cattle: changing sequelae with fetal maturation. Vet. Rec. 118:44-48.

Rüfenacht, J., P. Schaller, L. Audigé, B. Knutti, U. Küpfer, and E. Peterhans. 2001. The effect of infection with bovine viral diarrhoea virus on the fertility of swiss dairy cattle. Theriogenology $56: 199-210$.
Thobokwe, G., and C. Heuer. 2004. Incidence of abortion and association with putative causes in dairy herds in New Zealand. N.Z. Vet. J. 52:90-94.

Thobokwe, G., C. Heuer, and D. Hayes. 2004. Validation of a bulk tank milk antibody ELISA test to detect active infection with bovine viral diarrhoea virus (BVDV) in New Zealand dairy herds. N.Z. Vet. J. 52:394-400.

Thompson, C. 2005. 'Natural' BVD vaccination - The way to go? Vetscript 18:24-26.

Valle, P. S., S. W. Martin, and E. Skjerve. 2001. Time to first calving and calving interval in bovine virus diarrhoea virus (BVDV) seroconverted dairy herds in Norway. Prev. Vet. Med. 51:17-36.

Voges, H. 2006. Direct adverse effects of persistent BVDV infection in dairy heifers - A retrospective case control study. VetScript 19:22-25.

Waage, S. 2000. Influence of new infection with bovine virus diarrhoea virus on udder health in Norwegian dairy cows. Prev. Vet. Med. 43:123-135.

Wood, P. D. P. 1976. Algebraic models of the lactation curves for milk, fat, and protein production, with estimates of seasonal variation. Anim. Prod. 22:35-40. 